ANTIGUAS Y NUEVAS NOTICIAS SOBRE UNA FIGURILLA-SILBATO DE JAINA. CONTEXTOS, SONIDOS Y FORMAS

\author{
Laura Elena Sotelo Santos \\ Francisca ZalaQuett Rock \\ Centro de Estudios Mayas, Instituto de Investigaciones Filológicas, \\ Universidad Nacional Autónoma de México \\ Antonio Benavides Castillo \\ Instituto Nacional de Antropología e Historia, Campeche \\ Socorro del Pilar Jiménez Álvarez \\ Universidad Autónoma de Yucatán, Mérida
}

Resumen: El ensayo analiza una figurilla-silbato procedente de Jaina, que representa a un personaje femenino, bajo distintas perspectivas: arqueológica, acústica e iconográfica. Se expone un recuento de la información conocida de la pieza arqueológica, el contexto funerario en el que fue hallada y su relación con el sitio, así como con el ámbito cultural al que perteneció, y se analizan las propiedades sonoras de la pieza.

Palabras Clave: figurillas mayas, Jaina, arqueoacústica, iconografía.

ABSTRACT: We apply archaeological, acoustic, and iconographic approaches to analyze a feminine whistle from Jaina. We offer a summary of the available information about this piece, the funerary context in which it was found, its relationships with the archaeological site, and the cultural background of the society in which it was produced.

KEYwords: Mayan figurines, Jaina, archaeoacoustics, iconography.

RECEPCIÓN: 16 de febrero de 2015.

ACEPTACIÓN: 21 de abril de 2015. 


\title{
ANTIGUAS Y NUEVAS NOTICIAS SOBRE UNA FIGURILLA-SILBATO DE JAINA. CONTEXTOS, SONIDOS Y FORMAS
}

\author{
Laura Elena Sotelo Santos \\ Francisca ZalaQueTt Rock \\ Centro de Estudios Mayas, Instituto de Investigaciones Filológicas, \\ Universidad Nacional Autónoma de México \\ Antonio Benavides Castillo \\ Instituto Nacional de Antropología e Historia, Campeche \\ Socorro JimÉnEz ÁLVAREZ \\ Universidad Autónoma de Yucatán, Mérida
}

Este trabajo analiza, desde diferentes disciplinas y enfoques, una figurilla-silbato ${ }^{1}$ femenina de Jaina que pertenece a la colección de la Sala Maya del Museo Nacional de Antropología, en la ciudad de México. Se trata de una pieza hasta ahora única, pues a diferencia de otros instrumentos musicales hallados en la isla, ésta destaca por representar a una señora de la nobleza maya que tiene un códice en la mano derecha.

\section{Una figurilla con historia}

Comenzaremos con una breve "biografía" de la figura, distinguiendo los momentos históricos por los que ha pasado y las maneras en que ha sido interpretada (Hodder, 1987, 2001). Desconocemos el lugar y la fecha en que fue elaborada, si bien generalmente se le clasifica como propia del Clásico Tardío (550-900 d.C.). Es probable que fuese modelada y moldeada en algún asentamiento de las cuencas de los ríos Usumacinta o Grijalva en su tramo hoy tabasqueño, ya que allí se localizan varios de los centros productores de figurillas de barro café, y debido a las características de su pasta fina. Su creador decidió incorporar en ella los atributos de una mujer portando un códice y la función de un silbato. Arribó a Jaina por comercio, seguramente a través de la ruta costera que unía a muchas comunidades de Veracruz, Tabasco, Campeche y Yucatán. Pudo haber estado en uso como representación femenina y como silbato en diferentes prácticas so-

${ }^{1}$ El formato digital de la revista incluye la posibilidad de escucharla. 
ciales y rituales. Aproximadamente hacia el 900 d.C., un grupo familiar tomó la decisión de enterrarla junto con otras figurillas y cajetes como parte de un ajuar funerario (figura 1).

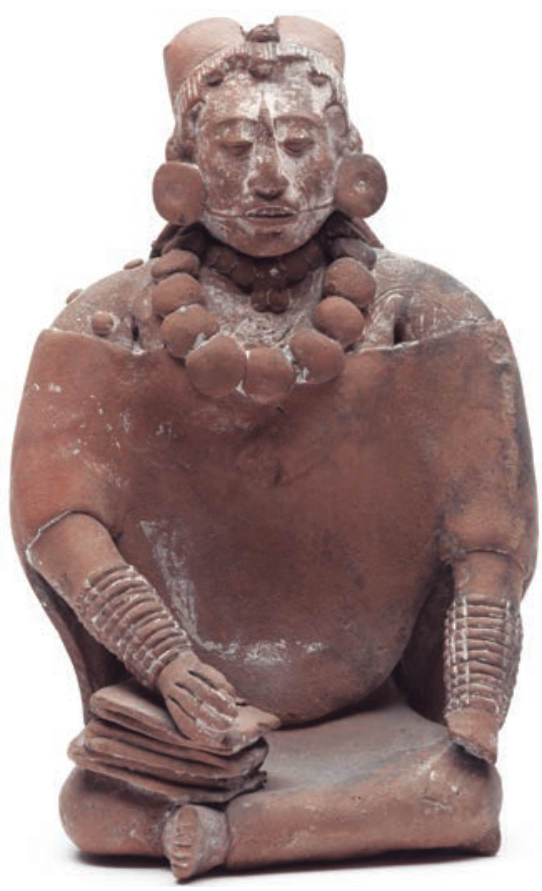

FIGURA 1. Figura-silbato de mujer. Archivo digital de las colecciones del Museo Nacional de Antropología. CONACULTA-INAH-CANON.

La figurilla estuvo enterrada un milenio, y en 1964 fue descubierta por Agustín Delgado, y fotografiada en ese momento por Luis Aveleyra, como parte de un programa para obtener piezas arqueológicas a fin de integrarlas a las colecciones del Museo Nacional de Antropología que se inauguró ese mismo año. El proyecto arqueológico fue dirigido por Román Piña Chan, entonces responsable de la curaduría de dicho museo. Tras su excavación fue trasladada a la ciudad de México y colocada en la bodega de la Sala Maya, pues, quizá por carecer de la mano izquierda, no fue seleccionada para ser exhibida. ${ }^{2}$

En 1997 la figurilla fue elegida para formar parte de la exposición Los Mayas, que se presentó el año siguiente en el Palazzo Grassi de Venecia. Más tarde regresó a México y fue exhibida en el Antiguo Colegio de San Ildefonso, en el centro histórico de la ciudad de México. Una segunda fotografía se publicó en el Catálogo

${ }^{2}$ En esa época se le asignaron los siguientes números: 10-78723, como número de inventario, y 5-1456, como número de catálogo del Museo. Además lleva anotado en su parte posterior "1964 excavación A, entierro 184", que corresponde al levantamiento de la pieza. 
de la exposición de Italia en 1998 y en su versión en español en 1999. Un dibujo de la pieza apareció publicado en 2011 en el libro de Stone y Zender titulado Reading Maya Art: A Hieroglyphic Guide to Ancient Maya Painting and Sculpture, como ejemplo de una escriba con su códice.

En 2003, al ser remodelada la Sala Maya, la figurilla se incorporó a la vitrina de Escritura, junto con una reproducción del Códice Tro-Cortesiano, reconociendo así su condición de representación de una especialista en la escritura. Diez años más tarde formó parte de la exposición Los mayas, revelación de un tiempo sin fin, en el Palacio Nacional de la ciudad de México, también integrada en la sala de escritura. La muestra viajó más tarde a Brasil y Francia, siendo expuesta en el Museo de la Ciudad de Sao Paulo, Oca, del Parque Ibirapuera (junio a agosto de 2014), y en el Museo parisino del Quai Branly (octubre 2014-febrero 2015).

\section{La figurilla-silbato en su contexto}

El sitio arqueológico de Jaina se ubica a $42 \mathrm{~km}$ al norte de la ciudad de Campeche, en el límite poniente del municipio de Hecelchakán y dentro de la Reserva de la Biosfera de Los Petenes. Su superficie es menor a $1 \mathrm{~km}^{2}$, pero el patrimonio cultural que conserva dice mucho de la sociedad maya que la habitó.

Debido a necesidades comerciales, los mayas crearon varias islas artificiales en el litoral occidental campechano, que sirvieron como puntos para el descanso y avituallamiento de los mercaderes navegantes que procedían de las regiones central y sureña de Veracruz, de la costa tabasqueña y del litoral septentrional yucateco. Algunas de estas localidades, yendo de Campeche hacia el norte, se conocen hoy como El Cuyo, Jaina, Isla Piedra (o Piedras), Yaltón e Isla Uaymil (figura 2).

Las evidencias poblacionales más tempranas registradas en Jaina datan de los primeros siglos de nuestra era, pero su auge ocurrió entre 600 y 700 d.C., cuando llegó a ser uno de los asentamientos más importantes de la costa oeste de la Península, coincidiendo con el desarrollo de las ciudades del Puuc. Fue abandonada a fines del periodo Posclásico (Benavides, 2010).

En el documento colonial llamado Códice de Calkiní, de fines del siglo xvı, la isla aparece mencionada como Hiná (2009: 81). El topónimo fue modificándose, como el hablar de la gente, y a principios del siglo xvIII (1703) varios mapas de navegantes franceses, ingleses y holandeses lo consignaron en sus cartas de navegación como Morros de Jaina, aludiendo a los montículos mayas visibles desde el mar, que servían como punto de referencia a las embarcaciones que surcaban la costa (Benavides, 2012: 47).

Román Piña Chan (2003: 180-225) estableció que el asentamiento era un centro religioso, administrativo y habitacional, corrigiendo las primeras interpretaciones de una posible necrópolis. William Folan y Luis Álvarez (1989) enfatizan su función como puerto donde el intercambio era de gran importancia. Benavides $(2007,2012)$ retomó la idea de un asentamiento completo, con habitaciones, cen- 


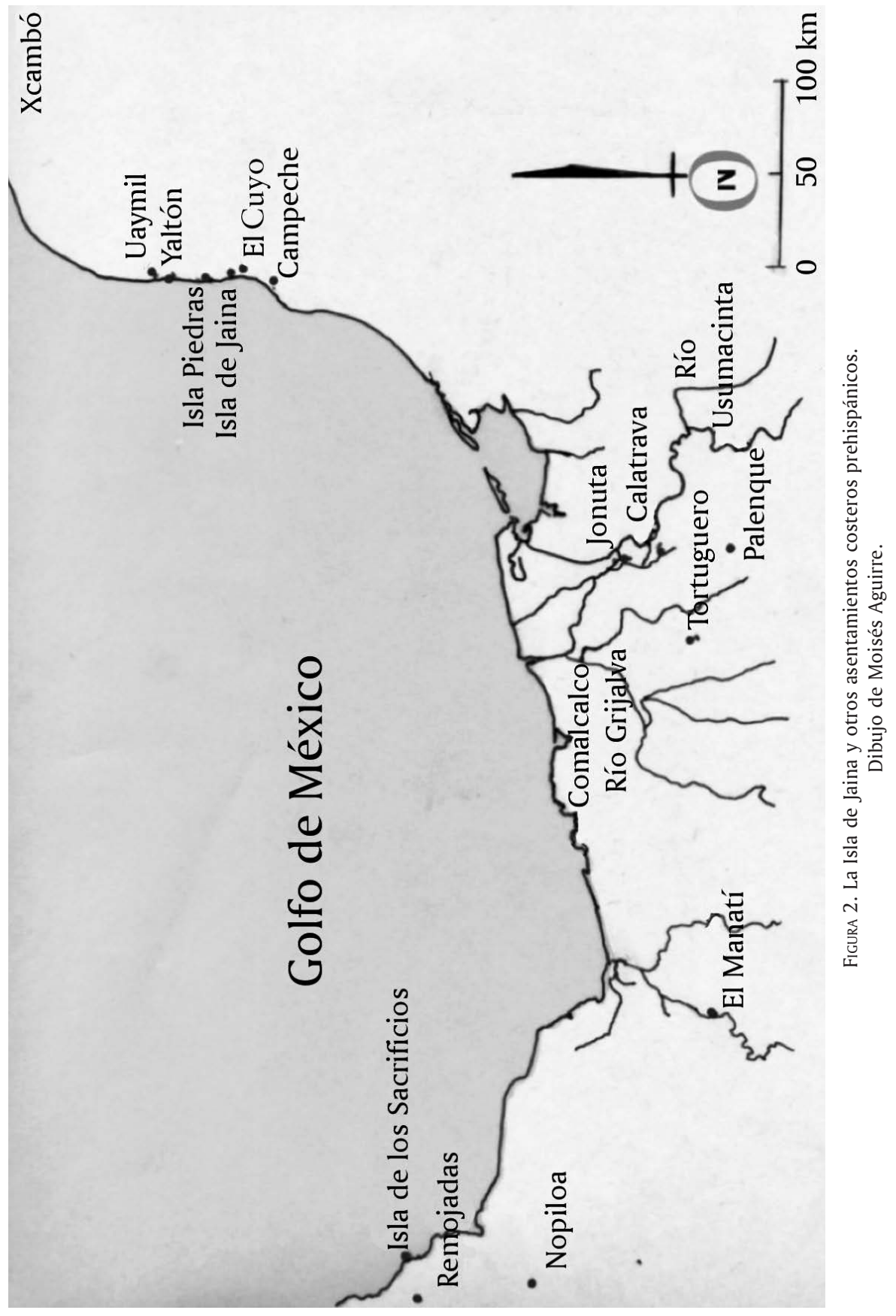


tro cívico-religioso y una ubicación estratégica para el comercio (figura 3). Concibe a Jaina como una entidad política pequeña pero poderosa no sólo por contar con su propio glifo emblema, sino también por sus nexos de intercambio con varias regiones mesoamericanas. Su centro político-administrativo estaba compuesto por una variedad de edificios públicos, como son el complejo Zacpool y el Zayosal. Las personas de alto rango habitaban las unidades habitacionales de mampostería alrededor de estos edificios, mientras que los demás grupos sociales vivían en casas de materiales perecederos o semiperecederos en la periferia.

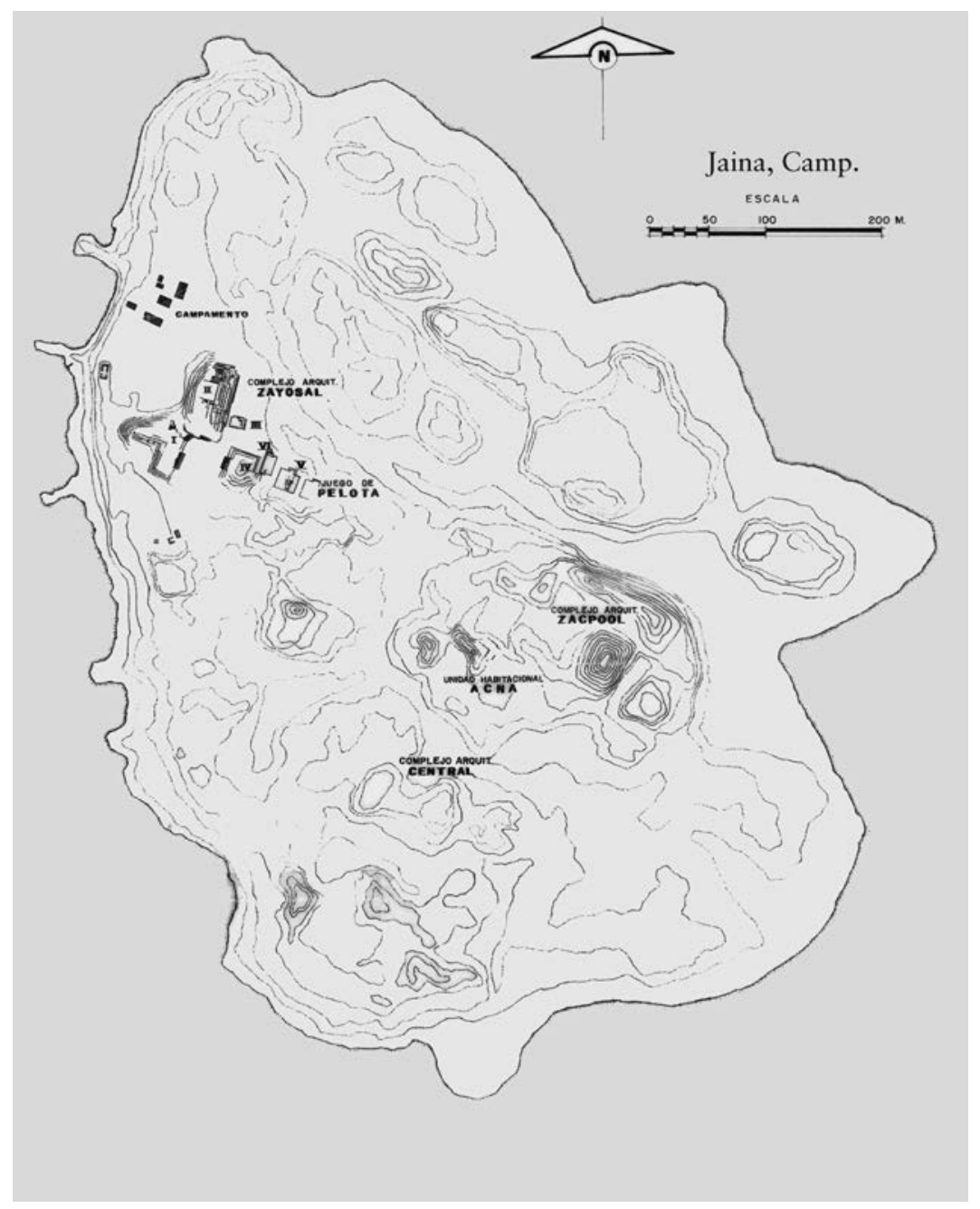

FIGURA 3. Levantamiento topográfico y planimétrico de Jaina. 
Ahora bien, se denomina con el nombre de figurillas de Jaina a un conjunto de pequeñas estatuas de barro cocido, de alta calidad artística, elaboradas durante el Clásico y que representan personajes masculinos y femeninos de diferentes edades y condiciones (Von Winning, 1980: 192-195). Son probablemente los ejemplos mejor conocidos del arte maya en pequeño formato y modelado en barro; se encuentran en museos (Foncerrada y Cardós, 1988; De la Fuente, 1992; Schele, 1997) y colecciones privadas (Von Winning, op. cit.) $)^{3}$ en diferentes lugares del mundo. Han sido encontradas en las costas de Campeche, muchas de ellas en Jaina, y otras en sitios cercanos, como las islas Piedra y Uaymil. Las excavaciones arqueológicas realizadas por el INAH han brindado información cultural acerca de los contextos funerarios de un grupo importante de ejemplos hallados en entierros junto con otros objetos también de cerámica, así como de concha, de hueso y de jade.

Por exploraciones previas y posteriores sabemos que estas esculturas de barro proceden de contextos funerarios, cuya riqueza ha permitido en el caso de Jaina recobrar información no sólo de la población misma, a través del análisis de los restos óseos, sino también de múltiples aspectos de la vida social y religiosa.

La pieza que analizamos procede de las excavaciones realizadas por el INAH en Jaina entre abril y junio de $1964 .{ }^{4}$ El entierro, numerado como 184 en esa temporada, contenía un ajuar funerario integrado al menos por cinco objetos elaborados en cerámica: un plato trípode (de tradición alfarera Baca rojo de uso costero) que pudo fungir como vasija capital, un cuenco de pasta gris fina y tres figurillas antropomorfas (figura 4$).^{5}$

En las fotografías se aprecia un corte circular alrededor de los objetos antes descritos, asunto que parece corresponder al "banqueo" o separación artificial de los elementos arqueológicos para su mejor exploración (figuras 5 y 6). No obstante, surge una duda respecto a la posición de los restos óseos, dado que en Jaina, por lo general, los entierros se hallan en posición extendida o en posición fetal, dato que no coincide con el corte circular arriba mencionado. Desconocemos si estuvo asociada a una persona masculina o femenina, debido a que no se especifica ni tampoco aparece en el informe.

Se han reportado tres tipos de entierros en Jaina: a) los primarios directos, colocados en el sascab o "tierra blanca", ${ }^{6}$ b) los primarios enterrados dentro de ollas

$3<$ http://research.mayavase.com/portfolio_thumbs.php?search="Jaina* $>$.

${ }^{4}$ En esa temporada se exploraron 12 pozos. Agustín Delgado excavó mayormente en el sector de playa ubicado al suroeste de la Estructura 1, donde registró una gran concentración de entierros, 190 en total (Delgado, ibid.: 22). Debido a que los resultados de dichos trabajos no están publicados en su totalidad, sólo se conocen pocos registros de distintos entierros y algunos detalles del contexto en que aparecieron las figurillas.

${ }^{5}$ Esta información deriva de dos fotografías de esa época, único material al que hemos tenido acceso, pues aparentemente no existe reporte escrito o ilustrado que permita abundar al respecto.

${ }^{6}$ Caliza que, molida, se utiliza para preparar mezclas para la construcción. 


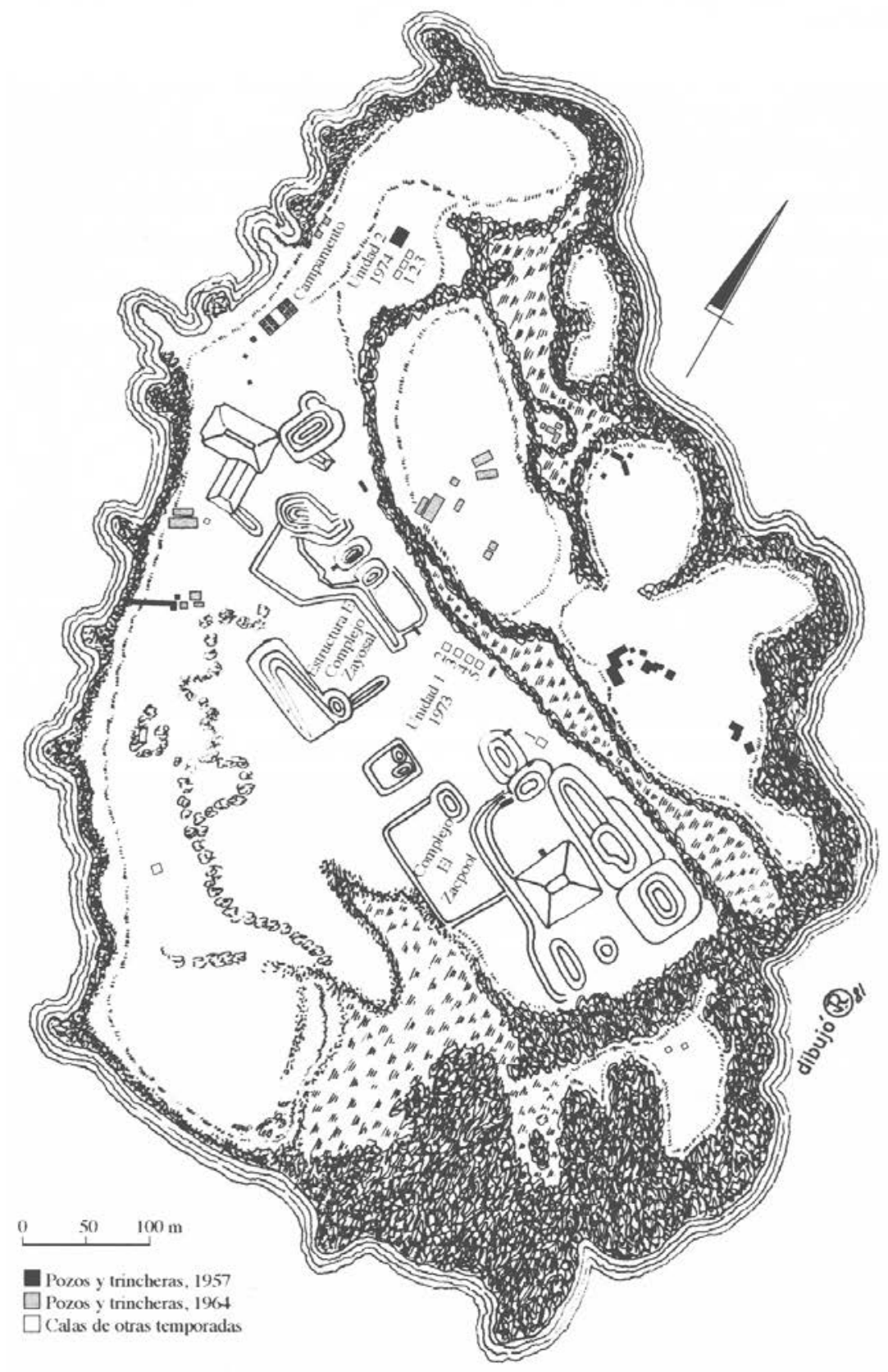

Figura 4. Ubicación de los pozos en las exploraciones de 1964. Modificado de Piña Chan, 1968. 

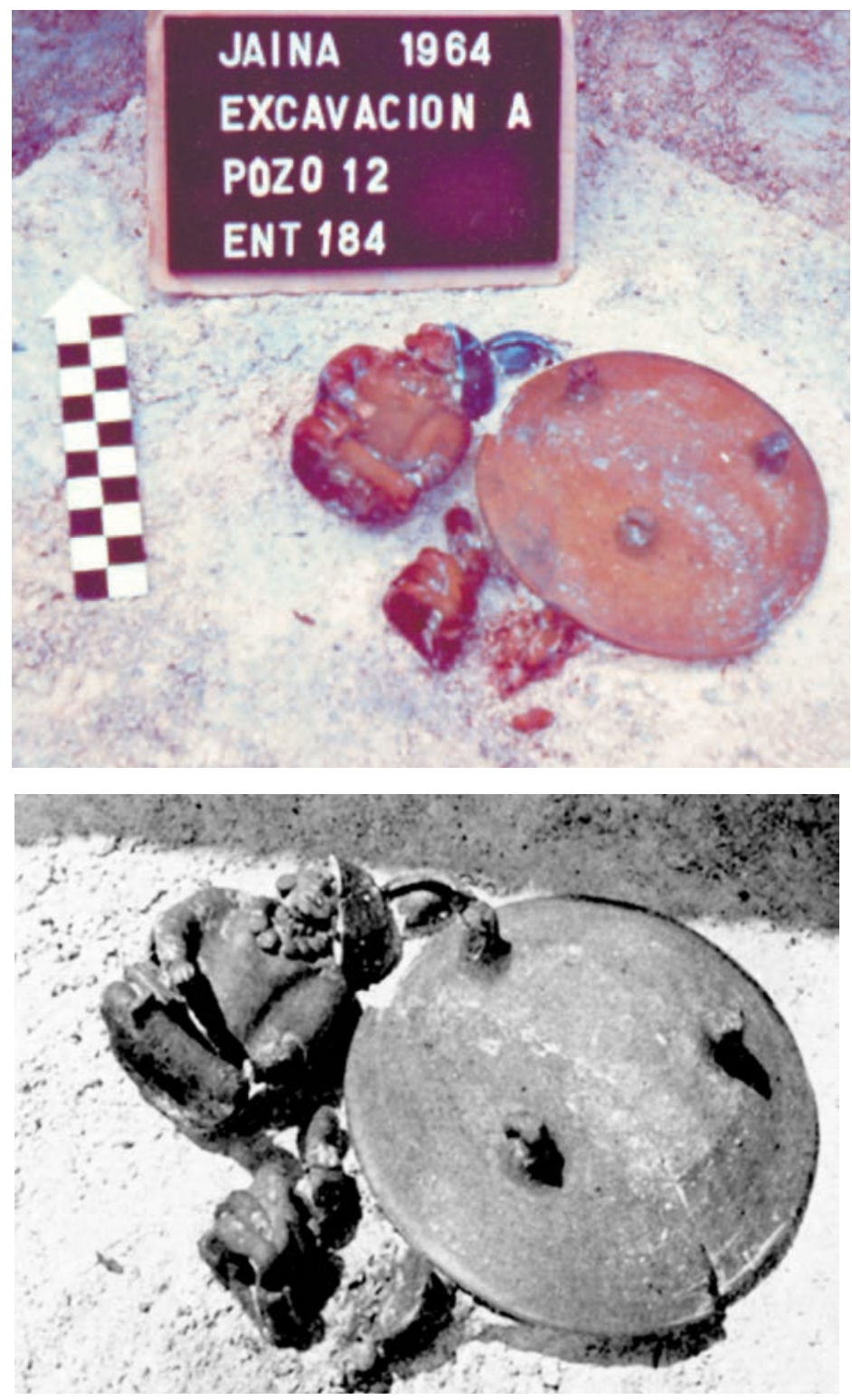

Figuras 5 y 6. Fotografías de la excavación del entierro 184, donde aparecen: a) el banqueo y las tres figurillas, la vasija capital y los cuencos de pasta fina; b) detalle (Aveleyra y Ekholm, 1966). 
grandes y c) los secundarios, en dos posiciones de enterramiento (flexionada o extendida) y en variedades como decúbito dorsal, lateral derecho o izquierdo, ventral y sedente (Serrano y López, 2007: 79). El primer y tercer tipo estaban destinados generalmente para adultos y jóvenes, y, en contadas ocasiones para infantes. Los adultos, tanto femeninos como masculinos, se ataban en bultos y se depositaban directamente en fosas en el suelo; el cráneo era cubierto con un plato trípode, denominado vasija capital. En los brazos flexionados del muerto, a la altura del pecho, se colocaban figurillas de cerámica modelada, moldeadas o mixtas. ${ }^{7}$ El segundo tipo de entierro es exclusivamente para infantes, que eran depositados dentro de una vasija globular. ${ }^{8}$ En este caso las figurillas pueden estar asociadas al esqueleto o colocadas por fuera de la vasija. El tercer tipo de enterramiento (secundario) se debe a la remoción de restos óseos para reutilizar el espacio.

Estas prácticas funerarias permiten reconstruir algunos aspectos de los rituales mortuorios realizados por los habitantes de Jaina, pues la existencia después de la muerte era concebida como una "vida en espejo" (Bonavides, 1992: 419) en la que el difunto requería de un atavío, de alimento y otros varios objetos considerados imprescindibles para su nueva existencia. En numerosas culturas las ceremonias de exequias también tenían sentido para la comunidad que las realizaba: separaban al recién fallecido del grupo al que pertenecía y garantizaban la existencia de la comunidad en el más allá, al cumplir cabalmente con el cuidado del cadáver, su disposición y el duelo (Van der Leeuw, 1964: 121-134).

En Jaina, la comunidad del finado acostumbraba pintar el cuerpo de rojo o amarillo, ataviarlo con una serie de adornos y muchas veces colocarle una cuenta de piedra verde en la boca. Todo ello encaminado a brindarle al muerto no sólo el indumento indispensable en su nueva existencia, sino también dotarlo de energías de renovación, mediante el color rojo, y de transformación, con el amarillo. La mortaja (tep, literalmente "envolver", con el sentido de "amortajar los muertos", según el Diccionario de Motul) con la que lo envolvían tenía la finalidad de despojarlo de su condición de vida corpórea y darle una cualidad permanente. ${ }^{9}$ La cuenta de piedra verde, según Landa, hacía las veces de moneda y se colocaba junto con maíz molido para alimentar al difunto en el más allá (1994: 181); de acuerdo a Bonavides, bien podía simbolizar el alimento que requeriría (op. cit.: 419).

\footnotetext{
${ }^{7}$ Otros elementos de los ajuares funerarios incluyen orejeras de obsidiana y de caracol, anillos, agujas de hueso, collares de concha y de jadeíta, punzones, cuchillos, caracoles, pectorales de concha, flautas, artefactos de sílex, navajas de obsidiana, malacates, pesas de red, metates, manos y machacadores de caliza y de basalto, entre otros.

${ }^{8}$ Con ellos se han recuperado vasijas miniatura, silbatos zoomorfos, puntas de proyectil pequeñas, navajas de obsidiana, caracoles marinos, cuentas de jadeíta, collares de cuentas de piedra verde, sellos de barro, malacates, cuentas de caracol marino, rondanas de hueso y flautas de barro (Delgado, 1989: 21).

${ }^{9}$ Con referencia a otras culturas, véanse Van der Leeuw (op. cit.: 187-188) y Chevalier y Gheerbrant (1988: 1063).
} 
Una vez dispuesto el cadáver en la sepultura, se encendía junto a ésta una hoguera, donde se quemaban algunos materiales. En este caso no se han analizado (Serrano y López, ibid.: 95), pero podríamos suponer que se trata de varias resinas como el copal o pom (Protium schippii), el copal blanco (Protium copal), el "incienso del país" o puk ak' (Notoptera leptocephala) o bien el chakah (Bursera simaruba), así como cera de abejas nativas y algunas plantas aromáticas (Tozzer, 1978: 75, nota 338; Arellano et al., 2003). Cabe recordar que para los mayas el fuego tenía una función purificatoria que preparaba al difunto para su nueva existencia. Es de suponer que las sustancias quemadas junto al occiso simbolizaban la transición de una condición a otra, de vida a muerte, y a la vez hacían posible una nueva existencia, como sabemos que ocurría en otras culturas (Van der Leeuw, 1964: 186).

Otro elemento a destacar son los patrones mortuorios detectados por Serrano y López (op. cit.) en el estudio de los 90 entierros excavados durante la temporada de 1973 y 1974, que son similares a los obtenidos en el mismo sitio durante las temporadas de 1948 y 1964 (Piña Chan, 1948, 1968). En general, los entierros femeninos se orientaban al sur, los masculinos al norte y los infantiles al oeste. Los ornamentos y figurillas son más frecuentes en hombres y niños que en mujeres. Los collares se asocian particularmente a niños; las conchas a sujetos femeninos, y los bezotes, abanicos y placas de concha a los masculinos (Serrano y López, op. cit.: 82).

Los antropólogos físicos asumen que el grupo al que pertenecían los individuos era socialmente heterogéneo, no formaban parte de la elite del lugar, entre quienes podría esperarse cierta homogeneidad en cuanto a la calidad del ajuar funerario. Consideran que las agrupaciones de entierros identificados parecen indicar que se trata de grupos domésticos o quizá familias que ocuparon el espacio por un largo periodo y enterraban a sus muertos en sitios aledaños a sus habitaciones (Serrano y López, op. cit.: 86). También hay que mencionar las modificaciones culturales en las piezas dentarias (mutilaciones, incrustaciones o ambas); en sólo tres entierros los individuos presentaron alteraciones dentarias y los objetos del ajuar fueron relevantes. Éstos podrían ser considerados de estatus superior a los demás (Serrano y López, op. cit.: 94).

En cuanto a los indicadores demográficos, Hernández y Márquez (2007), basados en el análisis de un centenar de esqueletos, plantean que el escenario de la población de Jaina corresponde a uno donde el crecimiento de habitantes estaba influido por la alta fecundidad de sus mujeres, con lo que se aseguraba la reproducción tanto biológica como social del grupo.

Hay entierros de adultos o de infantes que se distinguen por las figurillas antropomorfas u objetos de concha de fina manufactura, muestras de un probable rango social elevado. En la mayoría de los casos estudiados por Serrano y López (op. cit: 96) se encontraron figurillas desgastadas o incompletas, de pobre manufactura, que tenían la función formal de continuar con una norma funeraria en sujetos probablemente pertenecientes al pueblo común. No obstante, en otras 
temporadas, la mayoría de las figurillas se encuentran en buenas condiciones (Piña Chan, 1964; Barba, 2003; Benavides, 2006).

Por lo que respecta a estudios cerámicos, estas figurillas han sido clasificadas por varios investigadores, distinguiendo rasgos tecnológicos, estilísticos y químicos. Butler clasificó al grupo de personajes sedentes como Tipo X12b (1935: 649). Posteriormente, Piña Chan (1968: 66) los denominó Tipo I Modelado. A mediados de los años setenta, considerando elementos estilísticos, Corson (1976: 15) los conjuntó como tipo Jaina Grupo C, describiéndolos como facturados con una pasta color anaranjada o grisácea con desgrasante de textura media. Los objetos que muestra Corson tienen el torso modelado, pero su cabeza y brazos posiblemente fueron elaborados en moldes. El moldeado de las extremidades se sugiere debido a que tienen una uniformidad notoria en su estructura y dimensiones, aunque sus orejeras y collares fueron añadidos al pastillaje y algunas piezas presentan pequeñas incisiones en los hombros a manera de escarificaciones o tatuajes. También se las pintaba de color azul, blanco y rojo.

Estas piezas fueron clasificadas nuevamente, esta vez de acuerdo con ciertos agrupamientos diagnósticos de elementos químicos de la pasta. Goldstein (1979: 60) las ubicó como tipo Xac, y considera que eran comercializadas a larga distancia, debido a que han sido encontradas en varios sitios en el Bajo Usumacinta y en la cuenca del río Grijalva, por toda la costa del Golfo, así como en Comalcalco y Tortuguero. Es importante mencionar que Goldstein incluye una gran variedad de figurillas en este tipo, tanto modeladas como moldeadas, hechas con arcillas tipos XA y XC. Él diferenció un mínimo de ocho tipos de arcillas y concluyó que pudieron manufacturarse por lo menos en siete sitios distintos, entre ellos Comalcalco, Tortuguero, Calatrava y Jonuta (op. cit.: 52). Debido a la revisión de estos estudios y a sus investigaciones actuales, Benavides (2007) plantea que Jaina concentró y distribuyó la producción de objetos de arcilla procedente de diversas localidades, algunas tan lejanas como la parte media y sur de Veracruz (con una pasta de textura fina de color bayo), adquiriendo muchos objetos elaborados cerca de Palenque, en Comalcalco y Jonuta, con una pasta de textura mediana y de color marrón-rojiza, como el de esta figurilla. Agrega que existió una producción alfarera propia del occidente campechano y presente en Jaina, pero cuya localización precisa todavía se desconoce, lo cual se ve confirmado por el reporte de Delgado, donde registra la ubicación de un molde antropomorfo en la isla (1989: 27).

En términos de consumo y de intercambio, al igual que algunos de los sitios insulares del periodo Clásico Tardío, Jaina se muestra como un asentamiento consumidor de objetos cerámicos de procedencia lejana, y rector de su manufactura y distribución en los sitios localizados en la franja costera norte y occidental de la península de Yucatán. En otros términos, controlaba la producción y el intercambio de objetos de barro, tanto de uso doméstico como de figurillas-silbato y piezas manufacturadas con pastas finas. 


\section{El silbato}

Las excavaciones y los estudios epigráficos e iconográficos han dejado en claro que durante el periodo Clásico la música formaba parte de la vida cotidiana y ceremonial de los mayas. Así por ejemplo, algunos instrumentos imitaban sonidos de ciertos animales para atraerlos y cazarlos, mientras que otros acompañaban las ceremonias: sacrificios humanos, derramamiento ritual de sangre, conmemoración de fines de periodo, captura de prisioneros, Juego de Pelota, esparcimiento de semillas, danzas reales, entronización y fallecimiento de los gobernantes (Hammond, 1972a y 1972b; Houston y Taube, 2000; Houston, Stuart y Taube, 2006). Por ello consideramos que los músicos y los danzantes se encargaban de codificar y transmitir distintos elementos ideológicos al resto de la población, siendo ejes de comunicación entre grupos sociales.

Los variados instrumentos musicales prehispánicos mayas han sido clasificados por los etnomusicólogos como idiófonos, aerófonos y membranófonos (Von Hornbostel y Sachs, 1961; Flores y Flores, 1981; Méndez y Pimentel, 2010). Los contextos de estos instrumentos son variados; pueden hallarse en basureros, rellenos asociados con residencias de elite, construcciones monumentales, ajuares funerarios, patios y cuartos de las unidades habitacionales. Se han podido detectar ciertos cambios a nivel cronológico (desde el Preclásico hasta el Posclásico), aunque su uso y significado no se han estudiado a profundidad.

Los aerófonos (donde el generador del sonido es el aire oscilante) comprenden los silbatos, ocarinas (o flautas globulares simples y múltiples), trompetas o cornos de caracoles marinos con el vértice cortado a manera de boquilla, flautas de tubo recto singulares, doble o triples, y trompetas largas, de madera o cerámica.

La pieza que analizamos es un silbato de cámara sencilla, con un agujero en su espalda de $0.41 \mathrm{~cm}$ de diámetro, que conserva restos de la base de estuco que le aplicaron antes de pintarla, por lo cual creemos fue incluido en la manufactura original y sirve de digitación, y no es un orificio para "matar" el objeto. Es importante destacar que esta figurilla es la única de su tipo que tiene ese agujero (silbato tipo embocadura indirecta de borde ubicada en su brazo derecho, sedente, modelado y moldeado, con un agujero posterior), con un canal cilíndrico elipsoidal, cuyas medidas son las siguientes: largo $1.77 \mathrm{~cm}$, ancho "a" $1.09 \mathrm{~cm}$, ancho "b" $1.07 \mathrm{~cm}$ y alto $0.39 \mathrm{~cm}$. Con una boca romboidal de $1.07 \mathrm{~cm}$ de ancho "a", $1.22 \mathrm{~cm}$ de ancho "b" y $1.80 \mathrm{~cm}$ de largo.

\section{Análisis sonoro}

Para analizar las características sonoras del instrumento efectuamos la medición acústica de esta pieza en un laboratorio móvil o cámara sonoamortiguada, ${ }^{10}$ a fin

\footnotetext{
${ }^{10}$ Esta cámara está compuesta en su capa exterior por una hoja de triplay delgado, con una superficie reflejante que permite mantener fuera el ruido y la señal emitida en el interior. Un espacio
} 
de tener un medio controlado que nos permita efectuar comparaciones acústicas con otros instrumentos musicales.

En cuanto a los sonidos del silbato, lo ejecutamos a una distancia de $20 \mathrm{~cm}$ del micrófono, con soplidos suaves, medios y fuertes, a fin de definir la capacidad máxima y mínima de presión sonora que se puede aplicar en cada caso. ${ }^{11}$ Se detectaron varias frecuencias ${ }^{12}$ y obtuvimos espectrogramas que marcaron las frecuencias fundamentales con cada sonido y su presión sonora (decibeles), los cuales mostramos a continuación (figura 7).

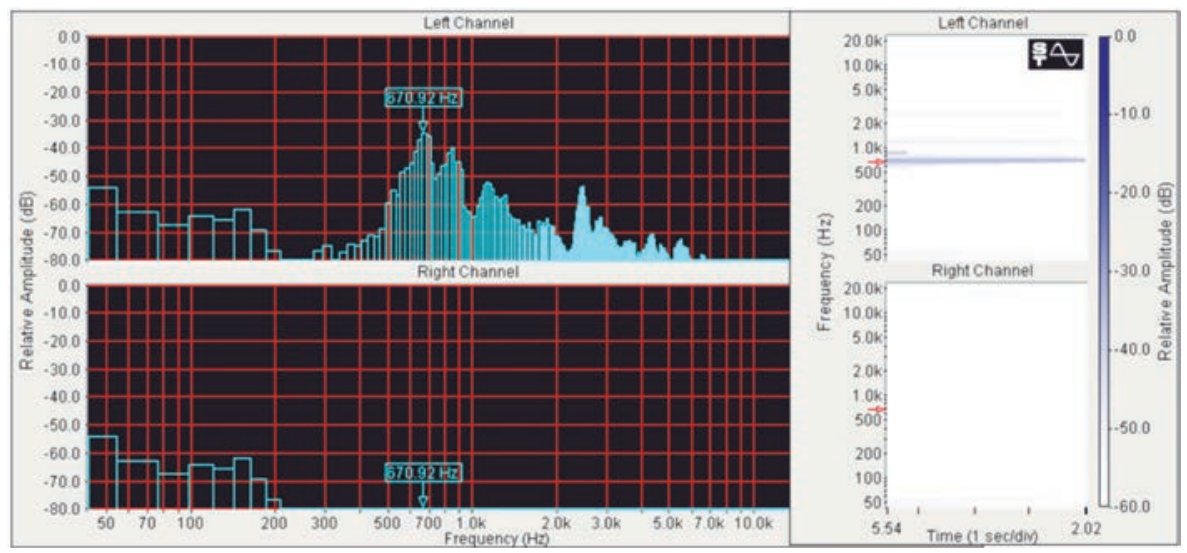

FIGURA 7. Soplido suave sin tapar el agujero. Se marca la frecuencia fundamental y los posteriores armónicos que se observan en los picos a una distancia proporcional de $1: 2$ de la frecuencia fundamental.

Estas frecuencias se pueden corresponder con los tonos occidentales, utilizando la convención musical, donde LA4 o A4 tiene una frecuencia de $440 \mathrm{~Hz}$ (figura 8).

Como los instrumentos musicales mayas son microtonales, con frecuencias un poco más altas o más bajas que en la escala occidental temperada de $440 \mathrm{~Hz}$, para medir los intervalos entre los tonos y semitonos producidos por dichos instrumentos utilizamos el sistema de Ellis (Olazábal, 2007: 81), que divide el semitono en 100 cents.

intermedio, con aire, impide la salida y entrada de ruido (en términos de no ser parte de la señal de los instrumentos). La tercera capa también es de triplay, con la misma función que la anterior. La espuma de absorción acústica que tiene adosada sirve como aislante y permite un registro más preciso de las frecuencias.

${ }^{11}$ Las grabaciones se efectuaron con instrumental y software especializado en acústica (micrófono ECM 1.000, Spectralab y Protools, interface Tascam US-122, cables de conexión instrumental).

${ }^{12}$ Que corresponden a la altura de un sonido, la cualidad que se expresa cuando decimos que un sonido es más grave o agudo que otro, correspondiendo los agudos a las frecuencias elevadas y los graves a las frecuencias bajas. 


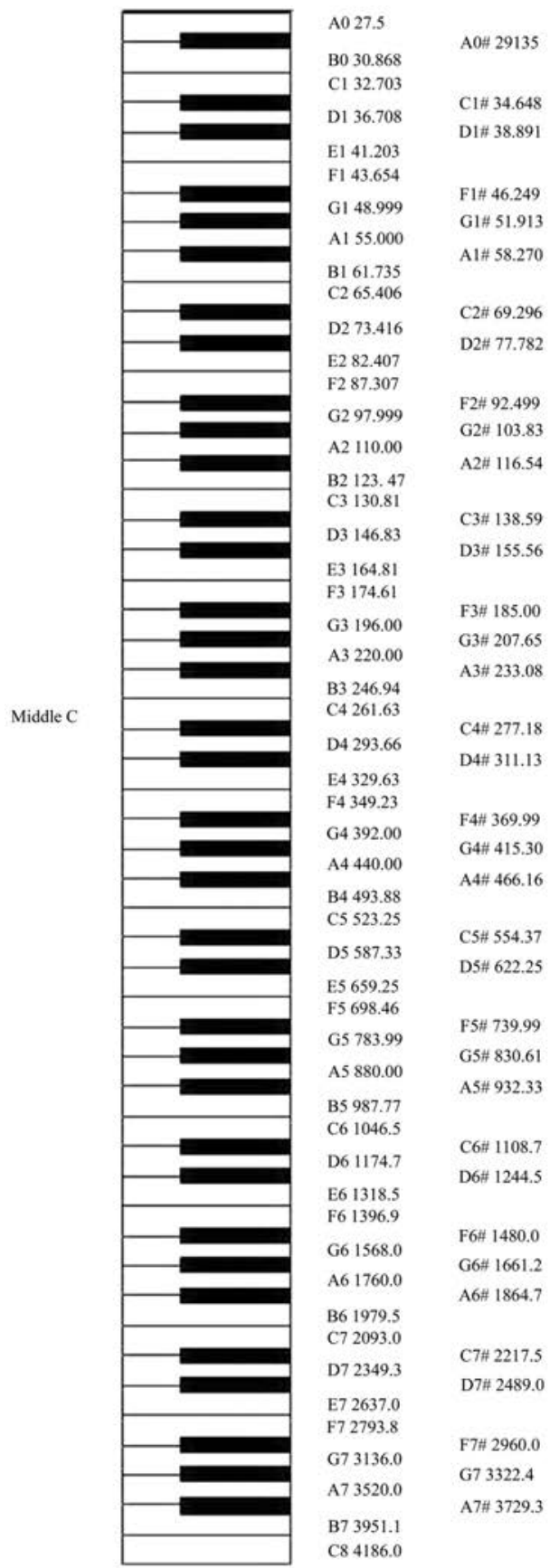

FiguRA 8. Base de conversión de frecuencias a tonos occidentales. 
En este caso, al analizar la acústica del silbato se obtuvieron diferentes tonos efectuando diversos soplidos con distinto volumen de aire y velocidad (pero que se logra con un sonido claro con los soplidos medios y fuertes). Estas frecuencias van desde Mi $5+30$ cents y Sol $5+3$ cents (figura 9). El agujero posterior sirve para bajar un semitono.

\begin{tabular}{|l|c|c|}
\hline \multicolumn{1}{|c|}{ Tipo de soplido } & $\begin{array}{c}\text { Frecuencia } \\
\text { fundamental (Hz) }\end{array}$ & $\begin{array}{c}\text { Relación con tonos } \\
\text { occidentales }\end{array}$ \\
\hline Suave & 670.92 (sonido poco claro) & Mi $5+30$ cents \\
\hline Medio & 737.56 (sonido claro) & Fa $5+94$ cents \\
\hline Fuerte & 785.61 (sonido claro) & Sol $5+3$ cents \\
\hline Suave tapando el agujero posterior & 670.92 (sonido poco claro) & Mi $5+30$ cents \\
\hline Medio tapando el agujero posterior & 699.76 (sonido claro) & FA $5+3$ cents \\
\hline Fuerte tapando el agujero posterior & 729.84 (sonido claro) & FA $5+75$ cents \\
\hline
\end{tabular}

FIGURA 9. Resumen de la mayor cantidad de cualidades acústicas que se pudieron obtener al interpretar el silbato 10-78723.

Llama la atención la existencia de silbatos que presentan una embocadura similar también ubicada en el hombro derecho, con una iconografía tanto masculina como femenina, y aunque cada uno posee atributos que lo hacen único, comparten la misma clasificación de la pasta, la cronología (Clásico Tardío) y, en los casos que han podido ser reportados, el contexto como ajuar funerario de Jaina.

Entre los mayas del periodo Clásico se ha podido traducir el nombre que le daban a los cantantes como k'ayo'm ${ }^{13}$ (Houston, Stuart y Taube 2006: 156), el cual se ha planteado que pudo servir como un título generalizado para músicos y cantantes (Regueiro, 2014: 86), que puede relacionarse con el término colonial yucateco k'ay, que se explica en líneas siguientes.

${ }^{13}$ Como aparece en el cuarto 1 de Bonampak, acompañando a un hombre que sacude una sonaja. 
Existen algunos registros de maya yucateco colonial y actual que nos acercan a los conceptos relacionados con los sonidos. En maya yucateco colonial el verbo uy se traduce como sentir, oír, escuchar, atender (Álvarez, 1980: 347), acción en que se involucran otros sentidos como el visual y el táctil, por lo que debemos considerarlo esencial para comprender la diferencia entre los conceptos mayas y los occidentales. De éste deriva u'uyik, que no sólo se refiere a oír, sino a todos los otros sentidos aparte de la vista. Su definición sonora es tan amplia que con el término k'ay pueden referirse a una gran cantidad de expresiones, como son música, canción, poesía, canto, gorjeo, pregón, amonestación de matrimonio, tonada (Barrera, 1980: 391). Derivados del vocablo anterior están los términos paklan k'ay, "cantar a coro", ki'ya k'ay, "armonía del canto", ki'yan pax, "armonía en instrumentos" (Barrera, op. cit.: 314).

Se registra otra palabra también traducida como "música", pax, pero en este caso relacionada en específico con los tambores, y paxil, como "tocada" o "composición", "música que se ejecuta" (Barrera, op. cit.: 635). Cabe señalar que solamente se aprecian distinciones claras en maya yucateco para referirse a silbato y flauta, por lo que las ocarinas y cornos formaban parte de uno de estos grupos, ya que, en el Diccionario Maya Cordemex, chul se traduce como "flauta", "chirimía", "corneta" y "tañer el chul", chulbil, como "tocando la flauta" (Barrera, op. cit.: 113). Por otro lado, la casa pública en la que se pudieron reunir los músicos y representantes era llamada popol na o "estera casa", lugar donde éstos se juntaban para tratar cosas de república y para preparar bailes para alguna fiesta del pueblo (Álvarez, op. cit.: 218).

Los sentidos son componentes indisolubles de la experiencia y conocimiento humano, esto se refleja en la creencia y práctica de los mayas, quienes en muchas ocasiones quemaban copal y enterraban a sus familiares con alimentos, e instrumentos musicales, relacionándolos con aspectos de su vida cotidiana y ritual. Los sonidos están relacionados con las formas en que se emplean en la sociedad, ya sea como una cosa en sí misma o en conjunción con otras actividades. Son un medio de expresión emocional, de entretenimiento, de comunicación, de representación simbólica de ideas y conductas, de respuesta física hacia ciertos estímulos y posibles trances, también ayudan a establecer normas sociales y reglas de conducta, por lo que validan las instituciones sociales y los rituales, además de contribuir a la continuidad y estabilidad de la cultura así como a la integración de la sociedad (Zalaquett, Nájera y Sotelo, 2014: 8).

La combinación de imagen e instrumento en un objeto puede ser atribuida a una forma de animación en la cual el objeto al ser soplado lo activa, haciendo que su forma representacional cobre vida (Halpering, 2014: 203). Es a través de esta interacción material-humana que los objetos se permean de agencia. En este caso queda la duda de si son sonidos que pudieron funcionar más bien como comunicadores y guía para la persona en su tránsito después de la muerte. 


\section{Aspectos iconográficos}

El arte funerario de Jaina pertenece a uno de los momentos de la historia de la escultura maya en donde la figura humana se convierte en el tema central de la representación. Aunque muchas veces parece seguir un esquema convencional, cada pieza alcanza singularidad cuando el escultor añade pequeños cambios en los detalles de los personajes (ornamentos, peinados, vestimenta, escarificaciones, etc.). Muchas de las esculturas halladas en Jaina muestran a la sociedad en sus varios aspectos: físico, vestuario, ornamentos, costumbres y actividades (figura 10). Con ello, las diferentes piezas alcanzan una individualidad cercana al retrato de personajes concretos, a la vez que algunas son símbolo de la nobleza en el poder. En este sentido podemos afirmar una identidad histórica en cada pieza, pues las representaciones humanas presentan formas y cualidades expresivas diferentes.

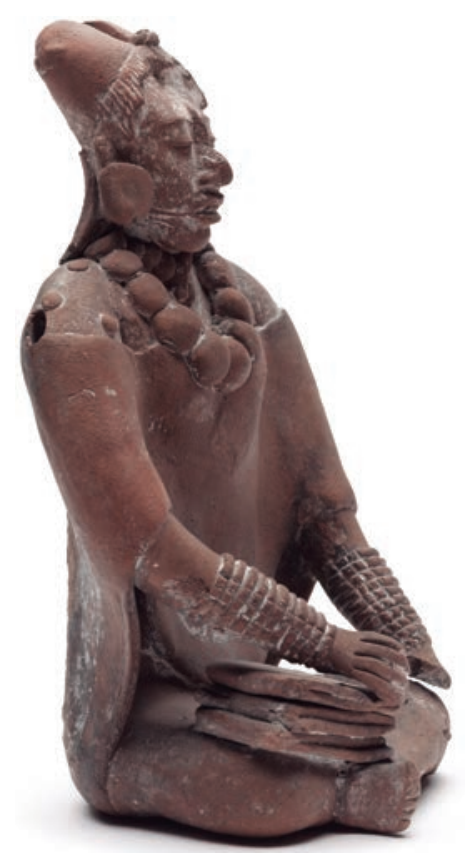

Figura 10. Vista lateral derecha de la figurilla. Archivo digital de las colecciones del Museo Nacional de Antropología. CONACULTA-INAH-CANON.

Aproximación iconográfica

Para el análisis iconográfico de esta pieza hemos seguido a grandes rasgos el método propuesto por Panofsky (2004) para el estudio del significado de las obras de arte. Este autor señala tres niveles de análisis: el primero es el que se refiere a la significación primaria o natural, mediante la cual se identifican las formas. 
El segundo se refiere a la significación secundaria o convencional, en la cual es posible reconocer alegorías en la combinación de los motivos artísticos, mientras que el tercer nivel, que es el de la significación intrínseca o contenido, permite el descubrimiento y la interpretación del contenido a través del estudio de los valores simbólicos.

\section{Análisis formal}

La escultura de barro 10-78723 tiene una altura de $15.5 \mathrm{~cm}$, ancho de $10.1 \mathrm{~cm}$, profundidad de $8.4 \mathrm{~cm}$, peso de $414 \mathrm{~g}$ y espesor de pasta de $0.31 \mathrm{~cm}$. Representa a una mujer maya sentada, con su pierna izquierda frente a la derecha. Cada una de sus manos está sobre la rodilla del mismo lado: la izquierda, hoy perdida, aún se percibe, pues se conserva la huella de sus dedos, y la derecha se apoya sobre un códice. Es una escultura en excelente estado de conservación, pues, salvo la mano izquierda, todos los demás detalles persisten; tenía un recubrimiento blanco y sobre él hubo pintura azul hoy casi imperceptible.

La pieza puede ser considerada en tres de sus lados como una escultura de bulto redondo, cuidadosamente elaborada. En su parte posterior fue tratada como un aerófono con características peculiares, entre las que resalta la boca romboidal en vez de trapezoidal, como es común en otros silbatos (figuras 11 y 12). Fue diseñada para asentarse y ejecutarse.

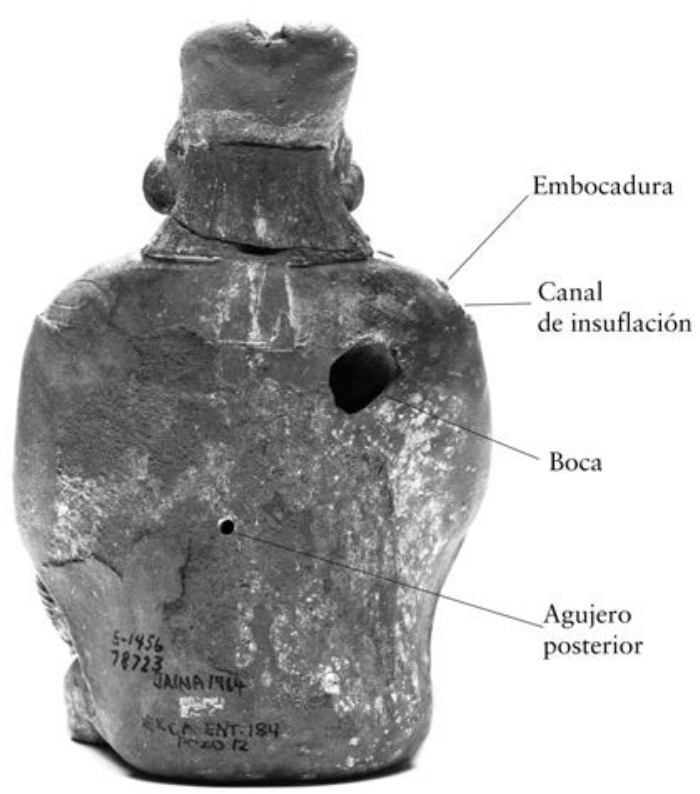

Figura 11. Descripción de los elementos que conforman el silbato. Archivo digital de las colecciones del Museo Nacional de Antropología. CONACULTA-INAH-CANON. 


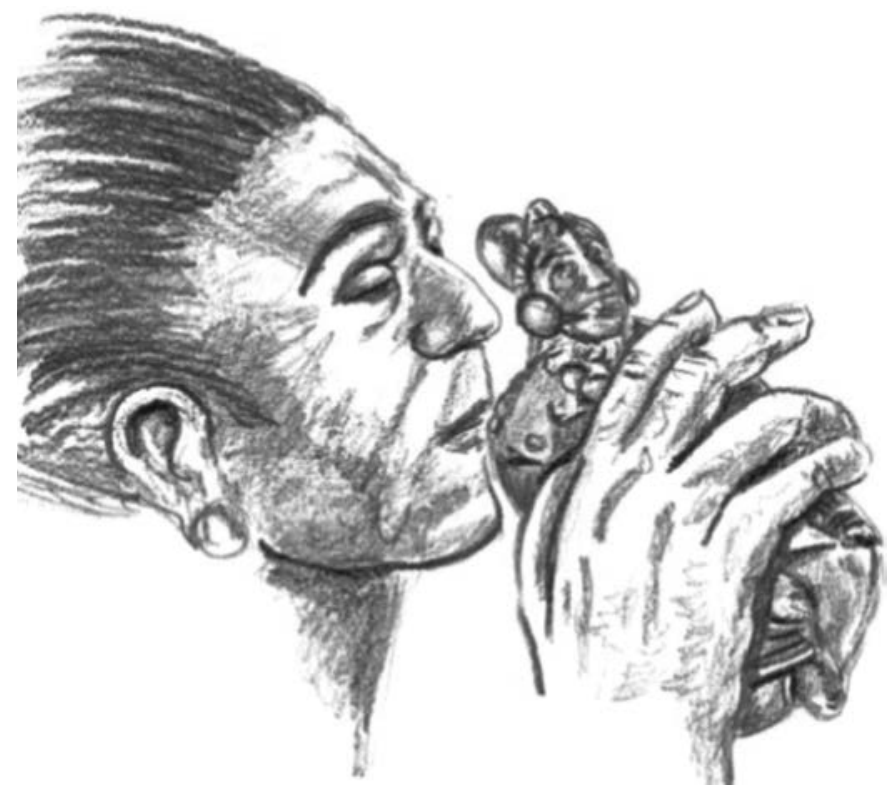

FIGURA 12. Dibujo que muestra la posición para ejecutar el aerófono. Dibujo de Moisés Aguirre.

De manera sintética podríamos decir que la estatua está integrada por cuatro lados, además de la base. De perfil semeja un triángulo rectángulo escaleno cuya base está constituida por las piernas, y la cúspide es la cabeza. Al ser una pieza concebida para apreciarse por su parte delantera, el escultor maya creó una especie de "itinerario de lectura", con el que generó un orden interno dentro de la imagen. Un cuidadoso observador de esta pieza podría hacer el siguiente recorrido visual durante su primer contacto: la mirada va de arriba abajo, regresa de nuevo, para fijarse en el rostro, visto de frente, y transita por el peinado, las orejeras y los collares, en particular el de grandes esferas que cuelga entre los senos. Al volver la mirada al rostro, desciende por los hombros e identifica las tres protuberancias en el hombro derecho; desciende hasta la cintura, sugerida por el huipil, hasta que abarca la totalidad de la pieza. La mirada se posa entonces en las dos grandes unidades de composición, el rostro y el cuerpo. Al integrar todos los elementos corporales, de atavío y de actividad, el espectador está en posibilidad de identificar de manera inequívoca a una mujer con un códice.

El artífice usó como eje de composición una línea vertical, imaginaria, que pasa por el mechón central del cabello, entre las cejas, la nariz y el ombligo. Ese eje dividió el cuerpo femenino en dos partes iguales y en equilibrio. La armonía resultante da a la pieza un carácter estático y solemne.

Aunque se conocen varios ejemplos muy semejantes que ahora están en diversos lugares, bien de Campeche, bien del resto del país y del mundo, cabe señalar 
que este silbato es único tanto por su estructura, como por su composición y sus elementos decorativos. En otros ejemplos la figura está sentada con la pierna derecha frente a la izquierda, y ambas manos reposan directamente sobre las rodillas. A diferencia de otras piezas análogas, el escultor de ésta destacó dos puntos focales: el códice y las tres protuberancias del hombro derecho. Estos componentes están fuera del eje de composición y al alejarse del centro marcan visualmente su importancia. El brazo orienta la mirada al códice, cuyo vértice coincide con los dedos del personaje, y corre paralelo a la diagonal del libro; se crea una ruta visual ascendente que va de la orilla de la falda a los dedos, pasando de nuevo por el códice, elementos verticales que le confieren fuerza y estabilidad a la obra (figura 13). En cambio, en el hombro derecho las formas circulares y redondeadas indican el punto donde está la embocadura del silbato.
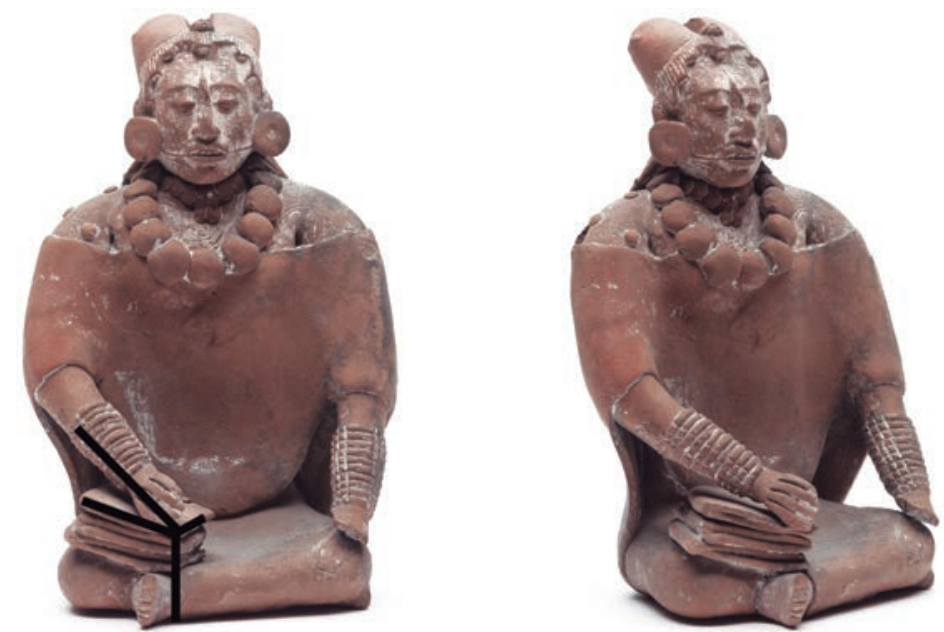

Figuras 13a y b. Vista del códice y eje de composición. Archivo digital de las colecciones del Museo Nacional de Antropología. CONACULTA-INAH-CANON.

El artista que realizó el molde de la cabeza de la figurilla logró una excelente factura en el rostro, desarrollado con maestría, y logró la perfección en el detalle: cejas, párpados, nariz, el "tabique artificial", como lo denominó Beatriz de la Fuente (1993: 217), boca, dientes, escarificaciones; todo está realizado con minuciosidad.

La mujer lleva el cabello partido a la mitad como un indicador femenino, presenta un corte "escalonado", frecuente en otras representaciones de la nobleza gobernante del periodo Clásico (Palenque, Lápida oval del Palacio; figurillas de Tabasco) (Gallegos y Armijo, 2004).

La señora, descalza, porta orejeras circulares, gargantilla, collar, pulseras, falda y huipil. Estas dos últimas prendas no presentan ningún adorno o diseño: el huipil deja desnudos los hombros, cubre los antebrazos y al frente cuelga abajo 
de la cadera; por el reverso, el artista figuró una pieza más larga, tal vez tratando de indicar que llegaba a la altura de los tobillos, al igual que la falda, semejante a las de otras figuras costeras o a las de Palenque y Yaxchilán.

El artesano creó en barro, a escala, un libro jeroglífico maya compuesto por tres secciones que recuerdan las tiras de papel, como los que ahora conocemos en repositorios europeos; colocó un tramo doblado de izquierda a derecha, otro de derecha a izquierda, y el último de nuevo de izquierda a derecha. Con ello representó dos características esenciales de los códices mayas: el formato de biombo y la unión de varias tiras de papel, como las que presenta el Códice TroCortesiano.

A diferencia de otras imágenes muy conocidas de diversos tiempos y latitudes en los que los escribas aparecen representados escribiendo, o sosteniendo los instrumentos propios de su sagrado oficio, como pinceles, estiletes y tinteros, la señora parecería estar a punto de abrir el códice (figura 14).

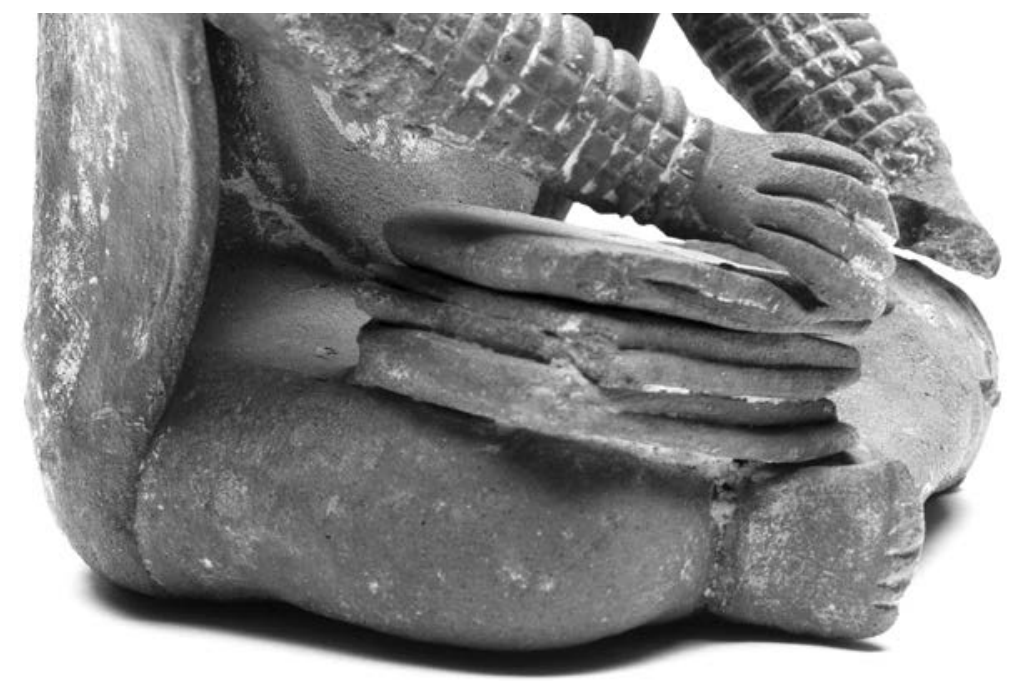

Figura 14. Detalle del códice. Archivo digital de las colecciones del Museo Nacional de Antropología. CONACULTA-INAH-CANON.

Respecto a su función como silbato, la embocadura se colocó intencionalmente en la parte posterior, sin romper la armonía visual de la representación antropomorfa. Fue puesta también en el costado derecho, ubicación que discutiremos más adelante.

La figurilla representa a un personaje femenino adulto, joven. Esta edad fue la más comunmente representada en el arte plástico maya del Clásico, quizá por significar la plenitud física del individuo, más que implicar una edad biológica. La señora está sentada, con los ojos abiertos y la boca entreabierta, lo cual indica que está alerta y tiene la posibilidad de emitir algún sonido. 
En ella se integraron diversas alteraciones corporales comunes en la antigua sociedad maya (Bautista, 2003). Identificamos cinco modificaciones permanentes en la figura: 1) la característica deformación craneal tabular oblicua, que el arte clásico maya exhibe y que registran múltiples estudios de antropología física; 2) los dientes limados, que apenas se perciben en la boca ligeramente abierta; 3) escarificaciones faciales (Bautista, op. cit.: 41), similares a las que se representan en otras piezas de Jaina, que están en ambas mejillas a la altura de los labios y conforman una línea horizontal. Von Winning (1980: 209) las clasificó como tipo a, dentro del grupo de figurillas femeninas con escarificaciones corporales en el hombro derecho mostrando tres abultamientos como "botones carnosos" (Bautista, ibid.: 41) o "discos pegados a la piel", de acuerdo con la denominación de Thompson (1946: 24), quien opina que pudieron haber sido usados sólo por mujeres, y que quizá denotaban rango, grupo o estatus; 4) tatuajes en el torso, representados a través de finas incisiones en el lado izquierdo, y 5) modificación de los lóbulos de las orejas mediante su perforación y distensión para portar orejeras.

Como modificaciones corporales transitorias están el corte de pelo escalonado, común entre hombres y mujeres nobles, y la denominada "prótesis nasal", es decir, el abultamiento que presenta entre las cejas, sobre el puente de la nariz, y que modifica su perfil.

Los adornos que porta son orejeras, gargantilla, collar y brazaletes. Mención especial merece la gargantilla, cuyo elemento central parece representar un caracol de la especie Oliva, trabajado a manera de cráneo humano, similar a ejemplos arqueológicos registrados en la región de los Chenes, en Uxul (figura 15) y en piezas que hoy forman parte del acervo del Palacio Cantón.

En tanto que aún quedan residuos de color azul en el cuerpo de la figurilla, es posible que estuviera pintada y detallada con varias tonalidades, como otras tantas piezas de barro halladas en Jaina.

\section{La señora y el códice}

Algunos mayas del periodo Clásico nacían dentro de un grupo social, otros ingresaban en él o adquirían una condición durante su vida: nobles, guerreros, comerciantes, campesinos, esclavos, etc., se reconocían a través de efigies culturales que incluían no sólo la apariencia de un individuo y su indumentaria, sino que implicaban conductas, saberes, creencias, prácticas, ceremonias y rituales, que les daba un sentido de comunidad, de historia, de memoria y de empeños compartidos. Las figuras halladas en Jaina retratan esta variedad y dan cuenta de una sociedad compleja, diversa, diferenciada. Cada una de ellas es una estampa cultural que brinda información de primera mano sobre el mundo social maya.

A la figura 10-78723 de la Sala Maya del Museo Nacional de Antropología la hemos denominado Xunáan yéetel u ju’un, "La dama con su códice", pues repre- 


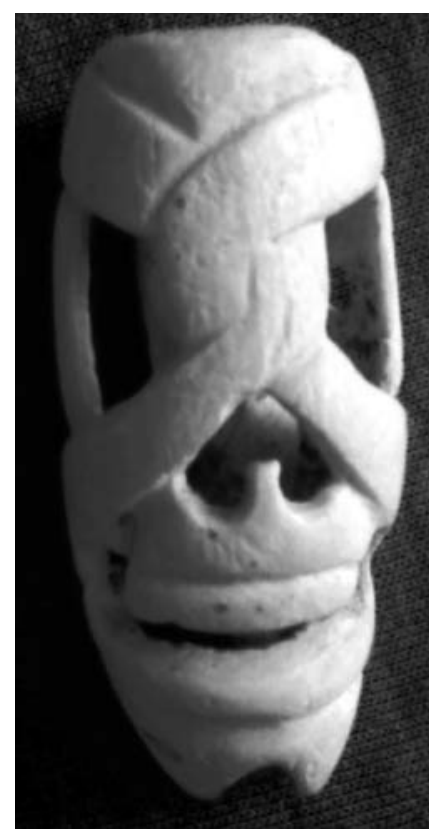

FIGURA 15. Concha de caracol Oliva tallada y perforada proveniente de Uxul. Excavaciones de 2010, Universidad de Bonn.

senta a una señora de la nobleza maya en el poder, sector social que durante el Clásico se identificaba por la indumentaria y las actividades: la deformación craneal, el corte de cabello, la prótesis nasal, las escarificaciones, los tatuajes, los "botones" en el hombro, la vestimenta, las joyas.

La vida de la nobleza maya transcurría con diferentes crisis de poder, desde el nacimiento, con la deformación craneal, hasta su entierro. Pasaba por varias pruebas y purificaciones, cada una de las cuales conducía a una nueva vida. A cada rito corresponde posiblemente una evidencia corporal que era reconocida en el grupo social; el cuerpo conservaba las huellas de los distintos tormentos, principalmente en la cabeza y el rostro; cada alteración, cada mutilación lleva a la adquisición de mayor conocimiento y jerarquía. En otros términos, los hijos de los nobles mayas al nacer tenían diferentes posibilidades de acopiar poder mediante la vida ritual; cada una de las ceremonias por las que pasaban, desde nacer hasta morir, era una vía para acumular poder no sólo social y político, sino también religioso; un valioso patrimonio que se conservaba incluso después de la muerte.

En el mundo clásico maya, los libros formaban parte de los emblemas de poder de la nobleza gobernante. En contextos arqueológicos se han hallado como parte de ajuares funerarios (Sotelo, 2002: 74) y es frecuente encontrarlos dibujados en las vasijas pintadas (Coe y Kerr, 1997). Generalmente se les representa de perfil, como un rectángulo compuesto por líneas paralelas horizontales, con 
lo que el pintor maya quería significar los dobleces que conformaban la larga tira de papel nativo, doblada y escrita. Tienen muchas veces una cubierta de piel de jaguar, elemento que los vincula con la nobleza y con conocimientos esotéricos. Los códices aparecen en escenas cuando están siendo escritos y, con menos frecuencia, como libros que están siendo leídos. Hay ejemplos en los que tanto escribas como lectores son seres sagrados; en otros, sólo son hombres. Esto se debe a la naturaleza divina de la escritura maya, a la que durante el Posclásico se concebía como un don sobrehumano, obra de Itzam Na (López Cogolludo, 1971: 254), dios supremo del panteón maya, por lo que cada códice es una transcripción del lenguaje divino, condensado en figuras que, a su vez, son susceptibles de transformarse en sonidos y, por ende, en palabras, si se conoce el código.

Dado que la señora no aparece con los instrumentos para escribir, es decir, el pincel y el tintero, podemos pensar que estamos ante una figura de mujer capaz de leer e interpretar un códice, ante una especialista que conoce el significado de los distintos signos y que puede transmitir esa información a los no iniciados. Por Diego de Landa sabemos que los códices pertenecían a los sacerdotes (1994: 181) y que una de sus funciones era dar a conocer los augurios de los distintos ciclos (ibid.: 89). Así pues, este silbato es la figura de una señora noble que ha pasado por distintos procesos de aprendizaje e iniciación.

\section{Conclusiones}

Una de las grandes interrogantes que presenta el estudio de la figurilla 10-78723 es el contexto en que fue hallada. Desconocemos si estuvo asociada a un hombre o una mujer. Tampoco conocemos todos los elementos que conformaron su ajuar funerario; de hecho, sólo sabemos de la presencia de piezas de cerámica. Este conjunto nos indica que el personaje enterrado falleció durante el periodo Clásico Tardío, ya que el plato que aparece asociado es de la tradición alfarera Baca rojo de uso costero ${ }^{14}$ y está fechado para el Clásico Tardío. Sólo dos sitios (Uaymil y Xcopté) tienen esta tradición Baca contemporánea a la época de inicios del horizonte Sotuta de Chichén Itzá. El Baca que se encuentra en Uaymil no es de función funeraria, sino doméstica y generalizada a los grupos de la elite residencial. Las otras vasijas fragmentadas al parecer son Gris fino, con una difusa silueta compuesta de la tradición Grijalva. Quienes lo sepultaron -o el mismo individuo- evidentemente tenían acceso a objetos procedentes de regiones alejadas, como la cuenca del Grijalva.

Las piezas del ajuar funerario reflejan las creencias escatológicas mayas durante el Clásico Terminal: los difuntos conservaban su identidad a lo largo del tiempo, y en el pensamiento maya es posible reconocerlos y comunicarse con ellos,

\footnotetext{
${ }^{14}$ Aún no se sabe si la producción es costera.
} 
pues son seres poderosos portadores de una fuerza cósmica que prevalece aun cuando su cuerpo desaparezca o se transforme. Así, más que concebir a la muerte como un hecho final, es un estado distinto a la vida, al que le corresponde un rito; concretamente un rito individual. En otros términos, quien era enterrado se consideraba con una existencia distinta a la terrenal, en la que su cadáver era, en cierta medida, continuación del cuerpo que tuvo en vida, con modificaciones constantes y sustanciales, hasta convertirse en huesos. Los restos óseos poseían una fuerza espiritual muchas veces mayor a la que el individuo tuvo durante su existencia en el mundo.

Así, el aerófono antropomorfo es un instrumento que ratifica el poder del difunto, es indispensable en su nueva existencia. El sonido que emite el silbato podría relacionarse con un grito (ahuat za), pues, según el Diccionario de Pío Pérez, el término para "tañer un instrumento" comparte la misma raíz que el vocablo utilizado para "llamar a gritos" e "invocar", ahuat pay (Álvarez, op. cit.: 78). Entonces, como gritar y silbar son formas primarias de comunicación humana, en la visión del mundo maya este instrumento daba la posibilidad al difunto de establecer relaciones con otras entidades en el más allá.

Todo lo anterior nos indica que la figurilla de Jaina, Xunáan yéetel u ju'un, representaba a una mujer noble que había ascendido en el mundo social, político y sobre todo, religioso, y que sabía interpretar los signos escritos. Era, en suma, una poderosa dama en la antigua sociedad maya.

\section{Agradecimientos}

Deseamos expresar nuestra gratitud al personal del Museo Nacional de Antropología y del Museo Fuerte de San Miguel en Campeche, por el apoyo brindado para realizar el estudio arqueoacústico de diversos silbatos, en especial a Diana Magaloni, Federica Sodi y Marco Antonio Carvajal. A Sara Novelo por sus observaciones y comentarios al texto, y a Cessia Esther Chuc por su traducción al maya yucateco de nuestra propuesta de denominación de la pieza. Esta investigación se realizó con apoyo del proyecto CONACYT 157146, Universos sonoros mayas. Un estudio diacrónico de la acústica, el uso, función y significado de sus instrumentos musicales. 


\section{BIBLIOGRAFÍA}

Álvarez, Cristina

1980 Diccionario etnolingüístico del idioma maya yucateco colonial. México: Universidad Nacional Autónoma de México, Instituto de Investigaciones Filológicas.

Arellano Rodríguez, Alberto et al.

2003 Nomenclatura, forma de vida, uso, manejo y distribución de las especies vegetales de la península de Yucatán. Mérida, Yucatán: Universidad Autónoma de Yucatán, Facultad de Medicina Veterinaria y Zootecnia.

Aveleyra, Luis y Gordon Ekholm

1966 “Clay Sculpture from Jaina”, Natural History Journal, LXXV (4): 40-48.

Barba Meinecke, Helena

2003 "Una visita al proyecto arqueológico Jaina en Campeche", Investigadores de Mesoamérica, 3: 52-72. Campeche: Universidad Autónoma de Campeche.

Barrera Vázquez, Alfredo (coord.)

1980 Diccionario Cordemex maya-español-maya. México: Ediciones Cordemex.

Bautista Martínez, Josefina

2003 "Huellas de alteraciones corporales en el hombre prehispánico", Canindé, 3: 37-58.

Benavides, Antonio

2006 "Una muñeca de Jaina", Mexicon, 3: 42.

2007 "Jaina en el contexto de las poblaciones del Clásico en el occidente peninsular”, La población prehispánica de Jaina. Estudio osteobiográfico de 106 esqueletos, pp. 13-32, Patricia Hernández y Lourdes Márquez (coords.). México: Programa de Mejoramiento del Profesorado, Secretaría de Educación Pública e Instituto Nacional de Antropología e Historia.

2010 "Jaina, Campeche: tiempos propuestos para su desarrollo prehispánico", La península de Yucatán: investigaciones recientes y cronologías alternativas, pp. 249262, A. Benavides y E. Vargas (coords.). México: Universidad Autónoma de Campeche.

2012 Jaina: ciudad, puerto y mercado. Campeche: Editorial Gobierno del Estado de Campeche (Colección Justo Sierra, I).

Bonavides Mateos, Enrique

1992 "Ritos de pasaje entre los mayas antiguos", Estudios de Cultura Maya, XIX: 397425.

Butler, Mary

1935 "A Study of Maya Mouldmade Figurines", American Anthropologist, 37 (4): 636667. 
Chevalier, Jean y Alain Gheerbrant

1988 Diccionario de los símbolos, versión castellana de Manuel Silvar y Arturo Rodríguez. Barcelona: Herder.

Códice de Calkiní

2009 Introducción, transcripción, traducción y notas de Tsubasa Okoshi Harada. México: Universidad Nacional Autónoma de México, Instituto de Investigaciones Filológicas, Centro de Estudios Mayas (Serie Fuentes para el Estudios de la Cultura Maya, 20).

Coe, Michael y Justin Kerr

1997 The Art of the Maya Scribe. New York: Thames and Hudson.

Corson, Christopher

1976 Maya Anthropomorphic Figurines from Jaina Island, Campeche. Ramona, California: Ballena Press.

Delgado, Agustín

1989 "Excavaciones en la Isla de Jaina”, Apuntes, 1: 13-45.

Flores Dorantes, Felipe y Lorenza Flores García

1981 Organología aplicada a instrumentos musicales prehispánicos: silbatos mayas. México: Instituto Nacional de Antropología e Historia, Museo Nacional de Antropología (Colección Científica, Arqueología, 102).

Folan, William y Luis Álvarez Aguilar

1989 "Jaina: su clima y niveles de mar a través del tiempo", Apuntes, 1: 6-12.

Foncerrada de Molina, Marta y Amalia Cardós de Méndez

1988 Las figurillas de Jaina, Campeche, en el Museo Nacional de Antropología: Corpus Antiquitatum Americanensium. México: Instituto Nacional de Antropología e Historia y UNESCO.

De la Fuente, Beatriz

1992 “El espíritu detrás de la piedra”, Artes de México, Nueva Época, 17. La colección mexicana del Museo Etnográfico de Berlín, pp. 45-64. México: Editorial Artes de México.

1993 La escultura de Palenque. México: El Colegio Nacional.

Gallegos, Miriam Judith y Ricardo Armijo Torres

2004 "La corte real de Joy Chan a través de las mujeres, hombres y dioses de barro. Estudio preliminar de género”, Los Investigadores de la Cultura Maya, 12 (2), pp. 304-318. México: Universidad Autónoma de Campeche.

Goldstein, Marilyn

1979 "Maya Figurines from Campeche, Mexico. Classification on the Basis of Clay Chemistry, Style and Iconography”, tesis de Doctorado en Filosofía. New York: Columbia University. 
Halpering, Christina

2014 Maya Figurines. Intersections Between State and Household. Austin: University of Texas Press.

Hammond, Norman

1972a "Classic Maya Music, Part I: Maya Drums", Archaeology, 25 (2): 124-131.

1972b "Classic Maya Music, Part II: Rattles, Shakers, Raspers, Wind and String Instruments”, Archaeology, 25 (3): 222-228.

Hernández, Patricia y Lourdes Márquez

2007 "El escenario demográfico de Jaina prehispánica durante el Clásico", La población prehispánica de Jaina. Estudio osteobiográfico de 106 esqueletos, pp. 3362, Patricia Hernández y Lourdes Márquez (coords.). México: Programa de Mejoramiento del Profesorado, Secretaría de Educación Pública e Instituto Nacional de Antropología e Historia.

Hodder, Ian

1987

"The Contribution of the Long Term", Archaeology as Long-Term History, pp. 1-9, Ian Hodder (ed.). Cambridge: Cambridge University Press.

2001 "A Review of Contemporary Theoretical Debates in Archaeology", Archaeological Theory Today, pp. 1-14, Ian Hodder (ed.). London: Polity Press.

Houston, Stephen y Karl Taube

2000 "An Archaeology of the Senses: Perception and Cultural Expression in Ancient Mesoamerica", Cambridge Archaeological Journal, 10 (2): 261-294.

Houston, Stephen, Karl Taube y David Stuart

2006 The Memory of Bones. Body, Being and Experience among the Classic Maya. Austin: University of Texas Press.

Landa, fray Diego de

1994 Relación de las Cosas de Yucatán. México: Consejo Nacional para la Cultura y las Artes.

López de Cogolludo, Diego

1971 Los tres siglos de la dominación española en Yucatán, o sea Historia de esta provincia. Austria: Akademische Druck-u, Verlagsanstalt, Graz, 2 vols.

Méndez, Alejandro y Agustín Pimentel

2010 "Tipología de los instrumentos musicales y artefactos sonoros arqueológicos de Mesoamérica y del norte de México", tesis de Licenciatura en Arqueología. México: Escuela Nacional de Antropología e Historia.

Olazábal, Tirso de

2007 Acústica musical y organología. Buenos Aires: Editorial Melos Ediciones Musicales.

Panofsky, Erwin

2004 El significado en las artes visuales. Madrid: Alianza Editorial. 
Piña Chan, Román

1948 Breve estudio sobre la funeraria de Jaina, Campeche. México: Gobierno del Estado de Campeche.

1964 "Jaina, Campeche”, Boletín INAH, 16: 4-8.

1968 Jaina, la casa en el agua. México: Instituto Nacional de Antropología e Historia.

Piña Chan, Román (coord.)

2003 Enciclopedia histórica de Campeche. Los orígenes, vol. 16, t. A. México: Editorial Porrúa y Gobierno del Estado de Campeche (Colección Pablo García).

Regueiro, María del Pilar

2014 "Música, canto y danza: un acercamiento iconográfico a las manifestaciones musicales mayas del periodo Clásico", tesis de Licenciatura en Historia. México: Universidad Nacional Autónoma de México, Facultad de Filosofía y Letras.

Schele, Linda

1997 Rostros ocultos de los mayas. Singapur: Impetus Comunicación.

Serrano, Carlos y Sergio López

2007 "Estatus social y contexto funerario durante el Clásico en Jaina, Campeche", La población prehispánica de Jaina. Estudio osteobiográfico de 106 esqueletos, pp. 63-96, Patricia Hernández y Lourdes Marquez (coordinadoras). México: Programa de Mejoramiento del Profesorado, Secretaría de Educación Pública e Instituto Nacional de Antropología e Historia.

Sotelo Santos, Laura E.

2002 Los dioses del Códice Madrid. Aproximación a las representaciones antropomorfas de un libro sagrado maya. México: Universidad Nacional Autónoma de México, Programa de Maestría y Doctorado en Estudios Mesoamericanos, Facultad de Filosofía y Letras e Instituto de Investigaciones Filológicas.

Stone, Andrea J. and Marc Zender

2011 Reading Maya Art: A Hieroglyphic Guide to Ancient Maya Painting and Sculpture. New York: Thames \& Hudson.

Thompson, J. Eric.

1946 "Tatooing and Scarifications among the Maya", Notes on Middle American Archaeology and Ethnology, 63: 18-25.

Tozzer, Alfred M.

1978 Landa's Relación de las cosas de Yucatan: a Translation. New York: Harvard University and Kraus Reprint Co. Millwood (Papers of the Peabody Museum of American Archaeology and Ethnology, XVIII).

Van der Leeuw, Gerardus

1964 Fenomenología de la religión, Elsa Cecilia Frost (trad.). México: Fondo de Cultura Económica. 
Von Hornbostel, Erich M. y Curt Sachs

1961 "Classification of Musical Instruments: Translated from the Original German by Anthony Baines and Klaus P. Wachsmann", The Galpin Society Journal, 14: 3-29.

Von Winning, Hasso

1980 "Las escarificaciones en la figurillas de Campeche", La antropología americanista en la actualidad. Homenaje a Raphael Girard, vol. I, pp. 191-210. México: Editores Mexicanos Unidos.

Zalaquett, Francisca, Martha Ilia Nájera y Laura Sotelo

2014 "Introducción”, Entramados sonoros de tradición mesoamericana. Identidades, imágenes y contextos, pp. 7-14, Francisca Zalaquett, Martha Ilia Nájera y Laura Sotelo (eds.). México: Universidad Nacional Autónoma de México, Instituto de Investigaciones Filológicas, Centro de Estudios Mayas. 